\title{
Contribuições do escritório de projetos à gestão do portfólio de produtos
}

\author{
Daniel Jugend ${ }^{a *}$, Sanderson César Macedo Barbalho ${ }^{\mathrm{b}}$, Sergio Luis da Silva ${ }^{\mathrm{c}}$ \\ a*Universidade Estadual Paulista, Bauru, SP, Brasil, daniel@feb.unesp.br \\ bUniversidade de Brasília, Brasília, DF, Brasil \\ 'Universidade Federal de São Carlos, São Carlos, SP, Brasil
}

\begin{abstract}
Resumo
Apesar de existirem muitos trabalhos sobre escritório de projetos e gestão de portfólio de produtos, são poucas as investigações que analisam esses elementos de maneira conjunta. Este artigo tem como objetivo identificar como o escritório de projetos pode contribuir com a gestão do portfólio de produtos. A pesquisa foi desenvolvida por meio de estudo de caso único em empresa de base tecnológica que renova seu portfólio de produtos com alta frequência e que possui a estrutura de escritório de projetos bem consolidada. Dentre os principais resultados, notou-se que é maior a participação do escritório de projetos nas decisões de revisão de portfólio do que naquelas relacionadas ao planejamento estratégico de produtos e que essa estrutura presta apoio à alta administração e às equipes de projeto para a aplicação dos métodos financeiros, de mapeamento e de avaliação de fases ao longo das atividades de gestão do portfólio de produtos.
\end{abstract}

Palavras-chave

Gestão do portfólio de produtos. Escritório de projetos. Empresa de base tecnológica.

\section{Introdução}

Por determinar o conjunto de produtos que a empresa utiliza para competir, a gestão de portfólio de produtos é tema de destaque no contexto do processo de desenvolvimento de produtos (PDP). Cabe a ela propor e aplicar mecanismos que garantam que 0 portfólio maximize a sua contribuição ao desempenho da empresa, em produtos atuais e projetos futuros, especialmente no que se refere a sua estratégia de inovação.

Cooper et al. (1999) e Kester et al. (2011) apontam que a gestão de portfólio de produtos é atividade relevante pois, em consonância com a estratégia de negócio, é responsável por determinar não apenas os projetos de novos produtos mas, também, revisões, atualizações e até mesmo decisões de descontinuidade entre o que é produzido e comercializado. Além disso, de acordo com esses autores, suas deliberações definem também quais projetos de produto devem ser acelerados, despriorizados e encerrados, e os recursos que devem ser alocados a cada um desses projetos.
Conforme Cooper et al. (1999), as decisões em portfólio de produtos possuem fundamentalmente os seguintes desdobramentos práticos para as empresas:

- Definição do conjunto de projetos de produtos que viabilizem a implantação da estratégia de negócio.

- Decisões sobre a alocação de recursos e investimentos entre os diferentes projetos de produtos (em termos de recursos financeiros e esforços de diferentes departamentos e especialistas).

- Seleção e priorização dos projetos de desenvolvimento de produtos.

Contudo, a tomada de decisão relacionada ao portfólio de produtos é aspecto considerado complexo para a gestão das empresas pois, além de estar inserida na etapa de pré-desenvolvimento do PDP (Florén \& Frishammar, 2012; Heising, 2012), as suas decisões também estão associadas aos valores políticos e de poder da empresa (Kester et al., 2011; WesseinbergerEibl \& Teufel, 2011), o que pode comprometer a 
otimização das escolhas relacionadas ao portfólio e ao bom desempenho do PDP.

Devido a esse caráter estratégico e complexo, são diversas as pesquisas nacionais e internacionais sobre gestão de portfólio de produtos que recomendam a aplicação de mecanismos formais e sistematizados para a sua gestão (Archer \& Ghasemzadeh, 1999; Cooper et al., 1999, 2000; Castro \& Carvalho, 2010; Mathews, 2011; Miguel, 2008; Mikkola, 2001; Oh et al., 2011). Dentre esses métodos, podem-se destacar como mais conhecidos e utilizados os financeiros, de pontuação, de ranqueamento, além dos mapas, gráficos, diagramas e do de avaliação de fases.

A gestão de portfólio de produtos é fator crítico e complexo especialmente para as empresas de base tecnológica (EBTs) que possuem como importante fator de competição o lançamento de produtos com alto conteúdo tecnológico. Pela sua própria definição, essas são empresas que realizam contínuas atividades de previsão tecnológica, desenvolvimento e transferência de tecnologia a um ou mais produtos ao longo do PDP (Toledo et al., 2008; Jugend \& Silva, 2010). Alguns trabalhos ainda pontuam que devido a essas demandas de inovação tecnológica de produtos, os métodos convencionais para a gestão de portfólio, especialmente o de caráter financeiro, podem não ser suficientes para predizer o desempenho dos produtos tecnológicos que as EBTs desenvolvem (Mathews, 2011; Scott, 2000).

Apesar dos escritórios de projetos, também conhecidos como Project Management Office (PMO), representarem estrutura organizacional que pode prestar apoio à gestão do portfólio de produtos, são poucos e recentes os estudos que investigam especificamente a sua contribuição ao gerenciamento do portfólio. Dentre eles identificaram-se os trabalhos de Artto et al. (2011) e de Unger et al. (2012), que visaram, sobretudo, demonstrar como o PMO pode fornecer apoio às atividades de coordenação, controle e suporte ao portfólio de projetos.

Este artigo tem como principal objetivo compreender, a partir de uma pesquisa qualitativa operacionalizada por meio de estudo de caso, maneiras pelas quais o PMO pode contribuir com as atividades da gestão de portfólio de produtos em uma empresa de base tecnológica (EBT). Para isso, buscou-se analisar como o PMO apoia as atividades de coordenação, controle e suporte do portfólio de produtos, bem como a sua participação na aplicação dos métodos tradicionalmente recomendados para a tomada de decisão em portfólio.

0 estudo de caso foi realizado em EBT que possui 350 funcionários, localizada na cidade de São Carlos, SP. Essa empresa foi escolhida porque renova seu portfólio de produtos com alta frequência e por possuir estrutura de escritório de projetos bem consolidada. Além disso, é conceituada como uma das principais EBTs do estado de São Paulo, tendo sido recentemente ganhadora do Prêmio Finep Sudeste e Nacional de Inovação. Particularmente, trata-se de empresa de alta tecnologia que possui centro próprio de $\mathrm{P} \& \mathrm{D}$ e que também realiza parcerias com universidades e institutos de pesquisa, além de parcerias tecnológicas internacionais, no desenvolvimento conjunto de produtos e tecnologias para atender a diferentes mercados e clientes. Esses fatos propiciaram ambiente adequado na empresa para reflexões e investigações sobre o tema, permitindo trazer para a literatura novos relatos sobre o problema de pesquisa em questão.

Inicialmente o artigo apresenta revisão teórica sobre o tema. Em seguida, aborda-se o método de pesquisa empregado e, posteriormente, discutem-se os resultados empíricos obtidos. Por fim, são delineadas as considerações finais.

\section{Revisão teórica}

Com o objetivo de abordar sucintamente os tópicos investigados neste artigo, a revisão teórica é dividida em duas partes. Inicialmente, trata-se o tema gestão de portfólio de produtos (tópico 2.1). Em seguida, no tópico 2.2, discute-se a atuação do PMO no contexto da gestão de portfólio.

\subsection{Gestão de portfólio de produtos}

As empresas que possuem atividades de desenvolvimento de novos produtos normalmente se defrontam com o desafio de gerenciar o portfólio de produtos. Conforme proposto por Cooper et al. (1999) e reforçado por diversas publicações (Castro \& Carvalho, 2010; Kester et al., 2011; McNally et al., 2013; Miguel, 2008; Oh et al., 2012), a gestão do portfólio de produtos deve cumprir fundamentalmente três objetivos básicos ao longo do PDP: alinhamento entre o portfólio de produtos e a estratégia de negócio, balanceamento e a maximização de valor.

A finalidade do alinhamento é traduzir a estratégia da empresa em um conjunto de produtos, de forma a considerar as linhas de produtos atuais ou futuras que serão responsáveis pela viabilização da estratégia, especialmente aquela vinculada à inovação (McNally et al., 2009; Florén \& Frishmmar, 2012). 0 balanceamento está relacionado ao mix de projetos de produtos e contempla questões como a avaliação do grau de inovação de cada um dos produtos que compõem o portfólio, riscos e recompensas previstos com o desenvolvimento desses projetos e prazos de 
execução (Oh et al., 2012; Padovani et al., 2012). A maximização de valor visa, basicamente, otimizar a relação entre recursos utilizados e retornos financeiros previstos com os projetos de produto (Kester et al., 2011).

Pesquisas anteriores levantaram dificuldades com que as empresas se defrontam para o cumprimento desses objetivos e para o bom desempenho da gestão do portfólio de produtos. Alguns trabalhos mencionam que por determinar com quais produtos uma organização irá competir, as decisões de portfólio estão associadas aos momentos críticos de predesenvolvimento do PDP, que tem como características centrais grande quantidade de ideias de projetos somada a elevada incerteza de resultados (McNally et al., 2009).

Clark \& Wheelwright (1993) e Jonas (2010) apontam que uma das principais causas de insucesso no desenvolvimento de novos produtos ocorre justamente devido a falhas gerenciais presentes nas atividades do planejamento do portfólio de produtos. Segundo esses autores, muitas empresas falham em nível estratégico, pois focam em projetos individuais e não os integram aos outros projetos e ao planejamento estratégico da empresa.

Archer \& Ghasenzadeh (1999) alertam que se por um lado as empresas possuem muitos projetos de produtos, por outro há limitação de tempo, recursos financeiros e humanos para o seu adequado desenvolvimento. Cooper et al. (2000) destacam ainda que as empresas gastam intensa energia gerencial para resolver problemas rotineiros e pressões de curto prazo, não conseguindo, dessa forma, dedicarem-se mais a questões referentes ao alinhamento entre desenvolvimento de novos produtos e suas respectivas estratégias.

Essas dificuldades podem levar a contínuas atividades de "apagar incêndios", o que é especialmente problemático na tomada de decisão sobre quais produtos desenvolver, manter ou retirar do mercado (Mikkola, 2001). Equívocos nesses momentos decisórios podem gerar problemas de projetos de produto, como a desarticulação entre os produtos desenvolvidos e os objetivos da empresa, baixa atratividade comercial, custo acima do esperado e desenvolvimento e transferência de tecnologias imaturas.

Visando minimizar essas dificuldades e, ao mesmo tempo, buscar melhores níveis de desempenho na gestão do portfólio de produtos, trabalhos como os de Cooper et al. (1999), Mathews (2011), McNally et al. (2009), Killen et al. (2008) e Oh et al. (2012) identificaram que as empresas que possuem melhor desempenho em portfólio de produtos são justamente aquelas que adotam mecanismos formais e sistematizados para conduzir essas atividades.

Dentre esses mecanismos formais e sistematizados para a gestão do portfólio de produtos já são bem reconhecidos os métodos financeiros (com a aplicação de análises como o payback, taxa interna de retorno e valor presente líquido, por exemplo), de pontuação, de ranqueamento, além dos mapas, gráficos, diagramas e do de avaliação de fases (Cooper et al., 1999; Castro \& Carvalho, 2010; Kester et al., 2011; Mathews, 2011; Mikkola, 2001; Oh et al., 2011; Pedroso et al., 2012).

Além disso, conforme sugerem os estudos de Archer \& Ghasenzadeh (1999) e Hauser et al. (2006), as decisões relacionadas ao portfólio de produtos podem ocorrer formalmente nas etapas de planejamento estratégico e de revisão de portfólio. 0 planejamento estratégico é associado a decisões que requerem maior período de tempo para serem concretizadas em forma de produtos e normalmente ele é vinculado ao médio e ao longo prazo (Cosner et al., 2007). A revisão de portfólio é caracterizada por avaliações sistemáticas dos resultados do planejamento estratégico, assim como análises mais imediatas de oportunidades e necessidades de novos desenvolvimentos ou descontinuidade de produtos atualmente produzidos e comercializados (Archer \& Ghasenzadeh, 1999; Kavadias \& Chao, 2007; Kester et al., 2011).

Apesar de existir vasta literatura que aborda o gerenciamento do portfólio de produtos, pouca ênfase tem sido dada à contribuição que os PMO podem dar à condução dessas atividades. 0 próximo tópico deste artigo apresenta sucintamente essa questão.

\subsection{Escritórios de projeto e sua atuação em gestão de portfólio}

No Guia PMBOK, escritórios de projeto são definidos como: “[...] uma unidade organizacional para a qual são designadas várias atividades relativas à gestão centralizada e coordenada dos projetos de sua área [...]" (Project Management Institute, 2008, p. 11).

Rodrigues et al. (2006) definem escritório de projetos como uma estrutura organizacional que fornece o respaldo necessário para que os profissionais possam gerenciar os projetos pelos quais são responsáveis, dentro dos prazos, custos e qualidade previamente planejados.

Embora não diretamente, as definições acima sugerem que os escritórios trabalham com conjuntos de projetos e, portanto, portfólio. Mais diretamente, para Crawford (2002), o PM0 é uma estrutura organizacional que tem por objetivo facilitar as atividades da gestão de projetos e proporcionar melhorias ao próprio processo de gestão da organização, o que pode ocorrer por 
meio da gestão do portfólio e do alinhamento de projetos com a estratégia corporativa.

É importante notar, entretanto, que no Guia PMBOK, o PMO exerce várias atividades em função do grau de controle sobre os projetos que the sejam designados. De fato o Guia PMBOK afirma: "[...] os projetos suportados ou administrados pelo PMO podem não estar relacionados ou serem gerenciados em conjunto [...]" (Project Management lnstitute, 2008, p. 11).

Apesar de o PMO representar uma estrutura que pode prestar apoio ao fornecer conhecimento especializado em gestão de portfólio (Jonas, 2010), são poucas e recentes as pesquisas que investigam e propõem práticas que vinculam o PMO à gestão de portfólio (Artto et al., 2011; Unger et al., 2012). Além disso, essas pesquisas não tratam especificamente da questão de portfólio de produtos, mas abordam portfólio de projetos gerais, as quais podem incluir desenvolvimento de produtos e, também, outros tipos de projetos, como o de implantação de tecnologia da informação e de mudança organizacional, por exemplo.

Unger et al. (2012) propuseram um framework baseado nas atividades de coordenação, controle e suporte e que pode orientar as atividades do PMO no planejamento e implantação do portfólio de projetos. A Tabela 1 apresenta esse framework.

Conforme pode ser visualizado na Tabela 1, as atividades de coordenação possuem basicamente a finalidade de alocar e realocar os recursos entre projetos e de facilitar a cooperação entre gerentes de projetos e funcionais envolvidos com o portfólio. As atividades de controle visam fornecer informações para a tomada de decisão e acompanhamento dos projetos que compõem o portfólio. Por fim, as atividades de suporte, além de estimularem a aprendizagem organizacional, têm também por objetivo oferecer serviços durante o planejamento e execução dos projetos.

Diante da revisão bibliográfica apresentada, é esperado que a presença da estrutura de Escritório de Projetos preste auxílio nessas atividades de coordenação, controle e suporte no gerenciamento de portfólio de produtos, assim como também colabore com a implantação e institucionalização dos métodos formais de gestão, de modo a apoiar a tomada de decisão sobre quais produtos desenvolver, manter e retirar do mercado (tais como os métodos financeiros, de pontuação, ranqueamento, checklists e mapas). lsto é, potencialmente, o PMO pode tornar o gerenciamento de portfólio mais sistemático e formal, o que tende a tornar as empresas mais maduras na condução dessas atividades (Killen et al., 2008; Kahn et al., 2006).

\section{Método de pesquisa}

Com o objetivo de compreender como o PMO pode contribuir com as atividades de gestão de portfólio de produtos, optou-se pela utilização da abordagem de pesquisa qualitativa, de caráter exploratório. A escolha dessa abordagem mostrou-se ainda mais adequada como melhor opção ao se verificar que a busca em conjunto das palavraschave Project Management Office and Portfolio em títulos e resumos presentes nos bancos de dados da Web of Science e Scopus resultaram em apenas sete artigos e que, desses, somente três constam como publicações em periódicos. Isso demonstra que o tema PMO relacionado com portfólio ainda é pouco explorado por pesquisas em gestão desenvolvimento

Tabela 1. Framework para as atividades do Escritório de Projetos no gerenciamento de portfólio.

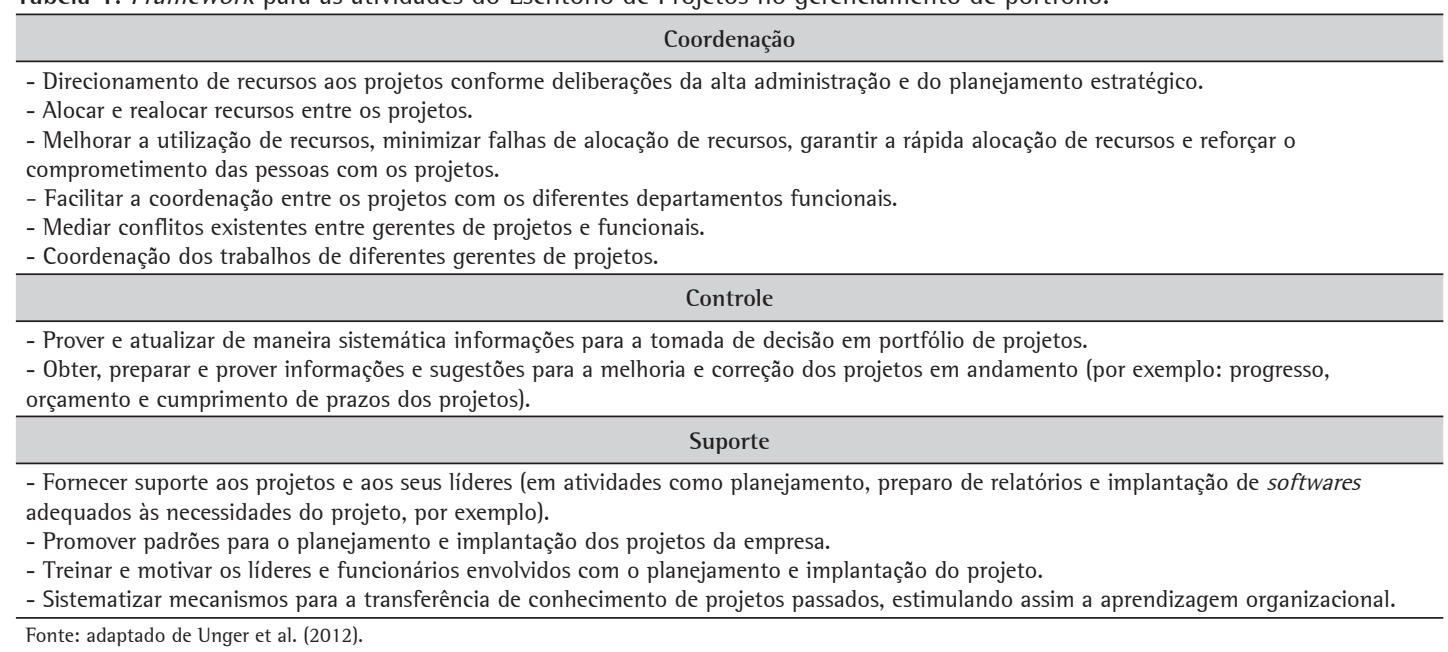


de produtos e de projetos. Além disso, por ter sido realizada a observação da experiência empírica de um caso único, não se propondo testar modelos teóricos de gestão mas elencar e relacionar evidências práticas no tema abordado, este estudo pode ser classificado como indutivo.

Compativel com a abordagem metodológica escolhida, julgou-se importante, portanto, a presença do pesquisador em campo, de modo a captar e entender as percepções dos profissionais envolvidos no PMO e com a gestão do portfólio de produtos na empresa pesquisada obtendo-se assim maior e melhor número de relatos e evidências do objeto de estudo.

Como procedimento de pesquisa foi utilizado o método de estudo de caso, o qual, segundo Yin (2005) e Miguel (2007), é adequado quando se busca maior compreensão sobre os fatos pesquisados. Além disso, segundo esses autores, o estudo de caso permite uma análise intensa de um número relativamente pequeno de situações, e às vezes o número de casos reduz-se a um, pois é dada ênfase ao amplo entendimento do fenômeno nessa única realidade escolhida para intensa investigação.

A escolha da empresa para o estudo de caso foi feita de maneira intencional. Além de ser conceituada por profissionais e acadêmicos envolvidos com o tema gestão da inovação e da tecnologia como uma das principais EBTs do estado de São Paulo, observou-se que a empresa atende aos seguintes critérios considerados indispensáveis para a realização desta pesquisa:

- Possui diversificado portfólio de produtos e que é renovado com alta frequência.

- Desenvolve e produz produtos para distintos mercados e atende a diferentes tipos de clientes (áreas médica, de defesa, ambiental e industrial).

- Possui a estrutura de Escritório de Projetos consolidada.

- Possui departamento interno de P\&D com a atribuição específica de desenvolver tecnologias.

0 roteiro de pesquisa foi construído com questões predominantemente abertas e que tinham a intenção principal de esclarecer o papel do PMO na gestão do portfólio de produtos da empresa. 0 roteiro foi construído tendo por base as pesquisas em gestão de portfólio de produtos conduzidas por Cooper et al. (1999, 2000) e Killen (2008). Em síntese, buscou-se identificar quais atividades o PMO realiza em termos de gestão de portfólio de produtos e, especialmente, quais métodos utiliza e como os resultados desse processo são desdobrados em decisões operacionais de gestão de projetos de produtos. Uma descrição mais detalhada do questionário aplicado se encontra no Anexo 1.
Após primeiro contato por telefone, o questionário foi enviado por e-mail ao gerente do escritório de projetos e previamente respondido. Em seguida, a empresa foi visitada, para a realização uma entrevista com esse gerente do escritório de projetos da empresa. Nesse momento, houve aprofundamento das respostas que já haviam sido previamente respondidas. Em etapa posterior, o mesmo questionário foi aplicado com três engenheiros e um técnico alocados no departamento de P\&D.

Além disso, seguindo os outros procedimentos recomendados para a realização de estudos de casos, as entrevistas foram acompanhadas de visita aos diferentes departamentos e também ao "chão de fábrica" da empresa e por conversas informais, quando foram obtidas novas informações e diferentes percepções a respeito do tema pesquisado (Miguel, 2007; Gibbert \& Ruigrok, 2010). Ou seja, as fontes de evidência utilizadas se basearam principalmente em entrevistas, observações e conversas informais.

\section{Estudo de caso}

Esse tópico trata da parte empírica da pesquisa. Inicialmente, a empresa é caracterizada. Em seguida, aborda-se a relação entre o escritório de projetos e a gestão do portfólio de produtos.

\subsection{Caracterização da empresa}

A empresa, criada em 1985, tem como sóciofundadores pesquisadores e funcionários oriundos do Departamento de Física da Universidade de São Paulo (USP). Atua, principalmente, nos segmentos de equipamentos médico-odontológicos, espacialmilitar e filmes finos. Dentre as principais famílias de produtos desenvolvidos e produzidos para atender esses segmentos de mercado, destacam-se os seguintes: microscópio cirúrgico oftálmico e laser fotocoagulador (área médica), sistemas de detecção a laser e unidades de apontamento e guiamento laser (área de defesa), medidor a laser para o controle de pneus e multiposicionador laser (área industrial) e subsistemas de imageamento para a incorporação em satélites de monitoramente ambiental.

Sua sede, onde está localizado o PMO e áreas funcionais como o P\&D, marketing e engenharia, situa-se no município de São Carlos, SP. Possui, também, escritórios comerciais nas cidades de São Paulo, Fortaleza e Porto Alegre. Conta com 350 funcionários, 18 deles alocados na área de P\&D, atuando diretamente em atividades de desenvolvimento de tecnologias, e outros 60 na função engenharia. 
Atende, majoritariamente, o mercado interno (a exportação contribui com menos de 10\% de seu faturamento). Tem como principais clientes os setores espacial militar; instituições governamentais, como o Instituto Nacional de Pesquisas Espaciais (INPE), a Força Aérea Brasileira e o Exército; e a área médicoodontológica (atendendo, principalmente, hospitais, clínicas e consultórios).

Considerando o desenvolvimento de produtos, a empresa desenvolveu cerca de 15 plataformas nos últimos cinco anos. A partir deles, diversos produtos derivados foram desenvolvidos.

\subsection{Gestão de portfólio de produtos na empresa}

Por se tratar de uma empresa de base tecnológica, a obsolescência de seus produtos é alta. Em um período de quatro a cinco anos qualquer um de seus produtos é considerado ultrapassado. Dessa maneira, a renovação contínua de seu portfólio de produtos é fator crítico para a empresa ser não apenas competitiva, mas para se manter no mercado.

As decisões sobre produtos e tecnologias a serem desenvolvidos ocorrem em duas etapas. Anualmente é realizado um encontro de planejamento estratégico que tem por finalidade apontar encaminhamentos de produtos e tecnologias os próximos três a cinco anos e, também, revisar os resultados de planejamentos estratégicos anteriores. Essa atividade envolve apenas os representantes da diretoria. Recentemente, foi estruturado um Conselho de Administração com membros externos representando um fundo de private equity. Mensalmente são realizadas reuniões da diretoria, nas quais as metas estabelecidas no planejamento estratégico são monitoradas, controladas e seu provável cumprimento é avaliado.

As decisões tomadas nas etapas de planejamento estratégico indicam a necessidade de desenvolvimento de tecnologias e produtos plataformas. Essas informações são consolidadas no final de cada ano de maneira a orientar os trabalhos de desenvolvimento para o ano seguinte. São informações direcionadas ao PMO e aos departamentos de engenharia e P\&D e que orientam planos de ação para o desenvolvimento de cada tecnologia ou plataforma de produto identificada como crítica para o período anual seguinte.

Como mecanismos para as revisões de portfólio ocorrem, mensalmente, as reuniões da diretoria e do conselho de administração. Nesses momentos, com a presença do gerente do $\mathrm{PMO}$, são informadas e diagnosticadas as necessidades imediatas de novos desenvolvimentos e revisadas as deliberações do planejamento estratégico, ou seja, busca-se, a partir de esforços mensais, a revisão sistemática do portfólio de produtos.

Ocorrem também as reuniões mensais de um comitê de produtos médicos, visto que essa é uma área civil considerada prioritária para a empresa, a qual conta com a participação de equipe multifuncional com representantes das funções $P \& D$, engenharia, produção, marketing e do PMO. Esse comitê tem uma função de interface entre as decisões da diretoria e do conselho de administração e o nível operacional dos projetos, sendo coordenado por um dos diretores.

$A$ área de projetos espaciais e militares e a área de filmes finos não contam com comitês. A primeira, porque os projetos são totalmente desenvolvidos sob a coordenação de uma das diretorias e contam com o suporte do PMO, e a outra, por ser considerada uma área de suporte às demais, cujos projetos são de tecnologias a integrarem os demais produtos da firma sendo, portanto, gerenciados com base nos projetos principais aos quais atendem.

A Tabela 2 demonstra a síntese das principais atividades que a empresa desenvolve no processo de gestão de portfólio de produtos. Vale notar a participação direta do PMO ao logo destas etapas.

A alta administração não apenas fornece apoio às atividades de gestão de portfólio de produtos como também é a principal responsável pelas suas decisões, cuja implementação é exercida operacionalmente pelo PMO. As seguintes ações operacionais relacionadas à gestão do portfólio de produtos foram institucionalizadas na empresa:

- À medida que os gerentes de projetos vão sendo treinados, eles assumem funções de gestão em programas de portfólio, sendo paulatinamente alocados na liderança de um ou mais projetos concomitantes de desenvolvimento de novos produtos.

- Quando há conflitos entre gerentes de projetos no que se refere à definição da alocação de recursos entre projetos, a alta direção normalmente baseia a resolução do conflito nas observações e ponto de vista do escritório.

- Em função de demandas apresentadas para melhorar o nível de desempenho de algum dos projetos individuais de produtos, o PMO possui autorização para alocar recursos internos durante tempo parcial junto a esses projetos.

- É atribuição do PMO a tarefa de aproximar as funções técnicas e gerenciais envolvidas com as decisões de curto prazo em portfólio de produtos. Para isso, além de intensificar a sistematização de mecanismos como reuniões e diálogos interfuncionais, o PMO também tem analisado a possibilidade de implantar softwares que facilitem a interação entre essas funções. 
Tabela 2. Principais atividades na gestão de portfólio de produtos da empresa.

\begin{tabular}{|c|c|}
\hline Etapa & Atividade \\
\hline 1 & $\begin{array}{l}\text { - Sistematicamente, o departamento de finanças em conjunto com o PMO levanta dados e informações sobre custos e receitas } \\
\text { mensais de cada um dos produtos da empresa. }\end{array}$ \\
\hline 2 & - Esses dados e informações são encaminhados aos diretores, que os analisam. \\
\hline 3 & $\begin{array}{l}\text { - Com base nessa análise, a direção, com o suporte do PMO, avalia o desempenho do portfólio e sugere decisões acerca } \\
\text { de atualizações, continuidade e descontinuidade dos produtos. Essas decisões são referendadas ou não pelo conselho de } \\
\text { administração. }\end{array}$ \\
\hline 4 & $\begin{array}{l}\text { - Uma vez ao ano ocorre a reunião estratégica, na qual os dados financeiros consolidados são avaliados, as decisões tomadas no } \\
\text { ano anterior são revistas ou referendadas e são gerados mapas tecnológicos por linha de produtos, nos quais se identificam as } \\
\text { iniciativas de novos projetos ou de projetos já em andamento que serão acrescidas, descontinuadas ou mantidas no ano vindouro. } \\
\text { Uma lista com os projetos que estarão em desenvolvimento no ano é gerada nessa reunião. }\end{array}$ \\
\hline 5 & $\begin{array}{l}\text { - Os mapas que detalham os projetos de desenvolvimento de novos de produtos e tecnologias são encaminhados de maneira } \\
\text { atualizada ao PMO e ao comitê de produtos médicos de maneira a orientar as atividades de início e controle de cada um dos } \\
\text { projetos aprovados. }\end{array}$ \\
\hline 6 & $\begin{array}{l}\text { - Ao longo do ano são identificadas oportunidades de novos produtos, as quais são consolidadas pelo PMO em uma descrição } \\
\text { de escopo do projeto e potencial de mercado. São então aprovadas após crivo dos diretores, presidente da empresa e conselho de } \\
\text { administração (informações e opiniões do pessoal de vendas são decisivas nesse momento) e então passam a fazer parte do plano } \\
\text { de trabalho dos diferentes departamentos. }\end{array}$ \\
\hline 7 & $\begin{array}{l}\text { - Para os projetos médicos há ainda o comitê de produtos médicos, que conta com a participação de representante do PMO. As } \\
\text { decisões desse comitê são transmitidas para os gerentes de projeto; assim como a situação de cada desenvolvimento é analisada e } \\
\text { a partir daí encaminhada à diretoria. Para outros projetos/linhas de produtos, a empresa não considera necessários esses comitês. }\end{array}$ \\
\hline
\end{tabular}

Dentre os métodos tradicionalmente recomendados para a gestão do portfólio de produtos, as avaliações financeiras constituem no principal mecanismo utilizado pela empresa. Mecanismos normalmente empregados para essa análise, como valor presente líquido e taxa interna de retorno, não são utilizados. Para essas decisões financeiras, com apoio técnico do PMO, são utilizados prioritariamente indicadores de margem de contribuição de cada produto, considerando margem bruta e previsões de faturamento com base no potencial de mercado de cada iniciativa para a tomada de decisão em portfólio de produtos.

Outros indicadores financeiros foram desenvolvidos com o objetivo de comparar a previsão de vendas aos custos correntes e previstos de cada projeto, mas não houve consenso na alta direção em torno dos indicadores propostos. Assim, optou-se por utilizar uma única medida baseada somente em previsão de venda para analisar o desempenho do portfólio de produtos.

Houve recentemente esforço para desenvolver indicadores de desempenho de projetos de produtos. 0 PMO propôs como um dos indicadores um índice de potencial do produto para a empresa, a ser aplicado em projetos da área médica. Esse índice compilaria dados de previsão de vendas com dados de custos de desenvolvimento, de maneira a chegar-se a um payback para projetos de produtos que compõem o portfólio. Apesar de essa proposta ter sido considerada positiva pelo conselho de administração, o indicador não foi efetivado para a gestão de portfólio de produtos, pois devido ao alto teor tecnológico incorporado aos seus produtos e a características dos mercados em que a empresa atua (sobretudo o business-to-business), o
PMO não conseguia obter dados confiáveis de previsão de vendas e, consequentemente, havia dificuldades quanto ao levantamento de informações financeiras.

Essas dificuldades ficaram claras com a seguinte observação do gerente do escritório de projetos:

Em nosso mercado, a inovação tecnológica é muito rápida e com isso não conseguimos realizar adequadas previsões de demanda para o médio e longo prazo. Isso dificulta a aplicação de métodos como o payback e taxa interna de retorno como meios para a avaliação dos projetos de novos produtos.

Conforme já mencionado, os mapas tecnológicos são elaborados ao longo do processo de planejamento estratégico e utilizados para orientar os trabalhos de desenvolvimento de produtos e tecnologias nos diferentes departamentos. A confecção desses mapas é responsabilidade da alta administração. Depois de prontos, eles são enviados ao PMO para o planejamento e implantação do que foi previamente deliberado.

No que se refere aos mapas como meios para a gestão do portfólio de produtos, um engenheiro que atua no P\&D mencionou:

A grande utilidade dos mapas para a empresa consiste em tornar visíveis os projetos de produtos que a empresa considera importantes para os próximos anos e, também, em orientar os esforços das diferentes áreas para iniciar os esforços de desenvolvimento desses produtos.

Não são adotados os modelos de pontuação, diagramas e outros métodos formais indicados na revisão bibliográfica deste artigo para gerenciar o portfólio de produtos. Os entrevistados mencionaram que isso se deve principalmente ao estágio de desenvolvimento gerencial da empresa, pois sua 
diretoria não considera efetiva a utilização desses métodos para a tomada de decisão em produtos. Ao questionar o porquê de não se usarem tais métodos, o PMO apontou que a não utilização desses métodos por parte da diretoria deve-se a que consideram tais análises uma sofisticação desnecessária para a tomada de decisão. Isso pode ser entendido sob o ponto de vista de que os sócios acompanham a empresa desde seus primórdios e conhecem todos os produtos e mercados em detalhes.

Quando da realização dessa pesquisa, o crescimento da empresa tinha gerado uma perspectiva real de implementação dos conceitos de fases ou gates, com medidas de atingimento de metas de prazo e escopo para a verificação do cumprimento das fases. A empresa planeja implementar painéis gerenciais com o uso de dados de prazo para verificar os riscos de cada projeto e tomar decisões de curto prazo quanto à alocação de recursos aos diferentes projetos. Esses indicadores são coletados pelo PMO e reportados às diretorias em uma base mensal.

Além de prestar apoio na condução do portfólio de projetos de produtos, o PMO também auxilia na sistematização e buscas de informação sobre necessidades de clientes e requisitos técnicos e tecnológicos de produtos de maneira a facilitar a tomada de decisões de portfólio de produtos pela alta administração.

Cerca de 70\% dos projetos de produtos da empresa referem-se a inovações do tipo incremental, enquanto $30 \%$ refletem esforços do tipo radical (que são também considerados os mais arriscados). A questão dos prazos configura-se, em geral, da seguinte maneira: $60 \%$ dos projetos de novos produtos são orientados ao curto prazo, normalmente de um a dois meses, em média, configurando melhorias em produtos e processos; enquanto 40\% são de longo prazo.

\section{Análise de resultados}

Este artigo reforça as proposições teóricas já demonstradas pela literatura nacional e internacional de que a gestão de portfólio de produtos é fator efetivamente relevante para as EBTs (Mathews, 2011; Scott, 2000; Toledo et al., 2008). No caso pesquisado, isso fica claro quando se observa a preocupação que a alta administração tem em controlar as decisões de portfólio de produtos para o longo prazo e os esforços que a empresa empreende na renovação, com alta frequência, do portfólio.

0 PMO da empresa pesquisada possui papel mais relevante nas decisões de revisão de portfólio no curto prazo do que naquelas vinculadas ao planejamento estratégico de produtos para médio e longo prazos.
Isso se evidencia na participação de membros dessa estrutura nas reuniões periódicas para as revisões de portfólio de produtos em conjunto com a diretoria e conselho de administração e, também, com eles integrando as equipes multifuncionais do comitê de produtos médicos.

A participação dos membros do PMO nas decisões de curto prazo pode ser considerada uma boa prática em gestão de portfólio de produtos pois, conforme sugerem trabalhos como o de Miguel (2008) e Kester et al. (2011), a formação das equipes multifuncionais tende a favorecer a qualidade na tomada de decisão em portfólio de produtos, uma vez que fortalece o compartilhamento de conhecimentos e informações entre as diferentes perspectivas funcionais para avaliações de aspectos técnicos, gerenciais e de mercado que esse processo decisório envolve.

Já no planejamento estratégico, o PMO não participa diretamente das decisões de desenvolvimento de produtos. Nesse caso, seu papel fica restrito a subsidiar a alta administração com informações sobre necessidades de clientes e requisitos técnicos e tecnológicos de produtos e a apoiar o planejamento e implementação dos projetos já aprovados em conjunto com os gerentes e equipes envolvidas.

A Tabela 3 compara o framework proposto por Unger et al. (2012) com as atividades que o PMO da empresa pesquisada efetivamente realiza.

Nota-se na Tabela 3 que a maioria das atividades propostas como contribuição do PMO para a gestão de portfólio, segundo o trabalho de Unger et al. (2012), estão efetivamente presentes na empresa. Apenas não são institucionalizadas: (1) a aprendizagem organizacional, pois, no caso pesquisado essa atividade ocorre mais pela presença de mecanismos informais do que propriamente de meios sistematizados pelo PMO; e (2) não é atribuição dessa estrutura a implantação de mecanismos que visem à motivação e treinamento dos funcionários envolvidos com os projetos de produtos. Por essas razões esses itens foram considerados como parcialmente presentes.

Observou-se também que o PMO da empresa pesquisada realiza algumas atividades de coordenação que não são previstas no framework proposto por Unger et al. (2012). Dentre elas destacam-se a autonomia que o escritório possui na alocação de seus funcionários em projetos de produtos que necessitam obter melhores níveis de desempenho e a atribuição que o PMO possui de fomentar mecanismos que intensifiquem a integração entre as funções técnicas e gerenciais envolvidas com a tomada de decisão em portfólio de produtos.

Além dos projetos de inovação incremental de produtos que são direcionados, sobretudo, para 
Tabela 3. Atividades do Escritório de Projetos na empresa pesquisada.

\begin{tabular}{|c|c|c|c|}
\hline Atividades do Escritório de Projetos na empresa pesquisada & Presente & $\begin{array}{l}\text { Parcialmente } \\
\text { presente }\end{array}$ & Ausente \\
\hline $\begin{array}{l}\text { Direcionamento de recursos aos projetos conforme deliberações da alta administração e do } \\
\text { planejamento estratégico. (Coordenação) }\end{array}$ & $\mathrm{x}$ & & \\
\hline Alocar e realocar recursos entre os projetos. (Coordenação) & $\mathrm{x}$ & & \\
\hline $\begin{array}{l}\text { Melhorar a utilização de recursos, minimizar falhas de alocação de recursos, garantir a } \\
\text { rápida alocação de recursos e reforçar o comprometimento das pessoas com os projetos. } \\
\text { (Coordenação) }\end{array}$ & $\mathrm{x}$ & & \\
\hline $\begin{array}{l}\text { Facilitar a coordenação entre projetos para os diferentes departamentos funcionais. } \\
\text { (Coordenação) }\end{array}$ & $x$ & & \\
\hline Mediar conflitos entre gerentes de projetos e funcionais. (Coordenação) & $\mathrm{x}$ & & \\
\hline Coordenação de trabalhos de diferentes gerentes de projetos. (Coordenação) & $\mathrm{x}$ & & \\
\hline $\begin{array}{l}\text { Prover e atualizar de maneira sistemática informações para a tomada de decisão em portfólio } \\
\text { de projetos. (Controle) }\end{array}$ & $\mathrm{x}$ & & \\
\hline $\begin{array}{l}\text { Obter, preparar e prover informações e sugestões para a melhoria e correção dos projetos em } \\
\text { andamento. (Controle) }\end{array}$ & $\mathrm{x}$ & & \\
\hline Fornecer suporte aos líderes de projeto. (Suporte) & $\mathrm{x}$ & & \\
\hline Promover padrões para o planejamento e implantação dos projetos. (Suporte) & $\mathrm{x}$ & & \\
\hline $\begin{array}{l}\text { Treinar e motivar líderes e funcionários envolvidos com o planejamento e implantação do } \\
\text { projeto. (Suporte) }\end{array}$ & & $\mathrm{X}$ & \\
\hline $\begin{array}{l}\text { Sistematizar mecanismos para a transferência de conhecimento de projetos passados, } \\
\text { estimulando a aprendizagem organizacional. (Suporte) }\end{array}$ & & $\mathrm{x}$ & \\
\hline
\end{tabular}

o desenvolvimento no curto prazo, a empresa demonstrou que cerca de 30\% de seus projetos de produtos são do tipo radical e para o longo prazo. Ao mesmo tempo que esse fato reflete a preocupação com o balanceamento do portfólio, confere-lhe também o caráter de ambidestralidade, uma vez que ao mesmo tempo em que a empresa visa aproveitar as suas capacidades e conhecimentos atuais (exploiting), o que relaciona-se à inovação incremental, também desenvolve novos conhecimentos e competências para a inovação radical de produtos (exploring).

Quanto à adoção de métodos formais para a gestão do portfólio de produtos e a participação do PMO nessa aplicação, a Tabela 4 contrapõe a síntese dos métodos citados pela revisão teórica com aqueles efetivamente adotados pela empresa.

Observa-se na Tabela 4 que a empresa aplica alguns dos métodos tradicionalmente recomendados para a gestão do portfólio de produtos e que o PMO participa da aplicação desses métodos. Notou-se ao longo do relato do caso que dentre os métodos utilizados as análises de caráter financeiro constituem o mecanismo mais frequentemente utilizado para a análise e deliberação do portfólio de produtos.

Contudo, a empresa demonstrou dificuldades para realizar previsões acuradas de demanda, o que inviabiliza o levantamento de indicadores como taxa interna de retorno e valor presente líquido. Isso ocorre porque, conforme relatado ao longo das entrevistas, é alto o grau de novidade tecnológica incorporada aos produtos que a empresa desenvolve, o que dificulta a realização de previsões mais acuradas de demanda. Esse resultado converge com o de pesquisas internacionais a respeito do tema, as quais já identificaram que as dificuldades para se realizarem previsões de demanda adequadas para produtos de alto conteúdo tecnológico constituem uma limitação presente nos métodos financeiros convencionais para análise de projeto de produto (Mathews, 2011; Scott, 2000).

Diferentemente do que propõe o estudo de Cooper et al. (2000), a aplicação do método de avaliação de fases ocorre na empresa apenas depois de iniciado o projeto dos produtos, isto é, na macrofase de desenvolvimento. Não são adotados mecanismos previamente institucionalizados para analisar-se ainda no predesenvolvimento se os projetos de produtos serão mantidos ou interrompidos e quais, dentre os mantidos, serão priorizados.

A empresa demonstrou disposição para intensificar esforços que levem a uma maior formalização da gestão do portfólio de produtos. A própria estrutura já consolidada de $\mathrm{PMO}$, somada à recente formação do conselho de administração com membros externos e a participação de equipe multifuncional para lidar especificamente com a gestão de portfólio de produtos, indicam essa tendência. Por outro lado, não se observou disposição do PMO para adotar outros métodos notoriamente reconhecidos para a gestão de portfólio de produtos, tais como os de pontuação, ranqueamento, gráficos e diagramas.

Nota-se que os resultados deste estudo de caso confirmam as expectativas levantadas na revisão bibliográfica de que a presença do PMO tende a favorecer a formalização da gestão de portfólio de produtos. Isso ficou claro no caso pesquisado ao se observar que o escritório da empresa apoia as 
Tabela 4. Síntese das práticas adotadas na gestão de portfólio de produtos.

\begin{tabular}{|c|c|c|c|}
\hline Métodos & Prática da empresa & Responsabilidade & $\begin{array}{c}\text { Benefícios citados pela literatura para a gestão do } \\
\text { portfólio de produtos }\end{array}$ \\
\hline Financeiros & $\begin{array}{l}\text { Utiliza apenas indicadores de } \\
\text { margem de contribuição de } \\
\text { projetos de produto e previsões } \\
\text { de faturamento. }\end{array}$ & $\begin{array}{l}\text { Apoio do Escritório de } \\
\text { Projetos e Departamento } \\
\text { Financeiro }\end{array}$ & $\begin{array}{l}\text { Utilização de métodos para análise financeira para a } \\
\text { avaliação econômica dos projetos de produtos. }\end{array}$ \\
\hline $\begin{array}{l}\text { Pontuação e } \\
\text { ranqueamento }\end{array}$ & Não adota. & - & $\begin{array}{c}\text { Permitem que os projetos de produtos sejam } \\
\text { pontuados pela equipe envolvida com a gestão de } \\
\text { portfólio e ranqueados e priorizados de acordo com } \\
\text { a sua média esperada de desempenho. }\end{array}$ \\
\hline Mapas & $\begin{array}{l}\text { Elaborados nos momentos } \\
\text { de planejamento estratégico } \\
\text { e utilizados para orientar os } \\
\text { trabalhos de desenvolvimento de } \\
\text { produtos e de tecnologias aos } \\
\text { diferentes departamentos. }\end{array}$ & $\begin{array}{l}\text { Desenvolvimento pela } \\
\text { alta administração. A } \\
\text { implantação conta com o } \\
\text { suporte do Escritório de } \\
\text { Projetos. }\end{array}$ & $\begin{array}{l}\text { A partir de métodos visuais, os mapas indicam } \\
\text { quais produtos podem ser desenvolvidos ao longo } \\
\text { do tempo. Essa técnica facilita a alocação de } \\
\text { recursos, o planejamento de prazos e a atribuição } \\
\text { de responsabilidades funcionais. }\end{array}$ \\
\hline Diagramas e gráficos & Não adota. & - & $\begin{array}{c}\text { A partir de mecanismos visuais, auxilia na avaliação } \\
\text { das prioridades e decisões de alocação de recursos } \\
\text { nos projetos de desenvolvimento de produtos. }\end{array}$ \\
\hline $\begin{array}{l}\text { Avaliação de fases } \\
\text { (stage-gates) }\end{array}$ & $\begin{array}{l}\text { Aplicação em projetos de } \\
\text { produtos já aprovados. } \\
\text { Utilização para controle de } \\
\text { escopo e prazo. }\end{array}$ & Escritório de Projetos & $\begin{array}{c}\text { Etapas formais para as decisões de aprovação das } \\
\text { ideias de produtos e de sua possivel continuidade } \\
\text { ao longo do desenvolvimento. }\end{array}$ \\
\hline
\end{tabular}

atividades de coordenação, controle e suporte no gerenciamento do portfólio de produtos, assim como também auxilia na aplicação dos métodos financeiros, dos mapas e da revisão de fases para a avaliação dos projetos de produtos da empresa.

\section{Considerações finais}

Ao investigar como o PMO pode apoiar a gestão do portfólio de produtos, este artigo contribui com o campo de conhecimento em gestão do PDP e de gerenciamento de projetos. Foram apresentadas práticas que podem orientar as atividades desses escritórios no gerenciamento do portfólio de produtos. Conforme sugere o artigo, essas práticas podem ser desdobradas em aspectos organizacionais, métodos formais, planejamento estratégico e revisões de portfólio.

Em termos organizacionais, o estudo de caso realizado complementa a proposta de Unger et al. (2012) ao identificar que, além das atividades de controle, apoio e suporte, o PMO também pode colaborar com o gerenciamento do portfólio de produtos ao estabelecer mecanismos que fomentem a integração entre os diferentes especialistas envolvidos com as decisões de portfólio de produtos e, também, participando das equipes multifuncionais envolvidas com o PDP.

Identificou-se que o PMO, no caso estudado, pode prestar suporte ao treinamento e aplicação dos diferentes métodos formais que apoiam o processo decisório em portfólio de produtos, tais como financeiros, mapas, gráficos, pontuação etc. É esperado, dessa forma, que os profissionais que atuem nesses escritórios disseminem conhecimentos para a aplicação desses métodos aos envolvidos com o conjunto de projetos de produtos da empresa.

Observou-se também que se por um lado o PMO apoia a alta administração e gerentes de projetos e funcionais na aplicação parcial dos métodos financeiros, mapas e de avaliação de fases, por outro não são aplicados os métodos de pontuação, ranqueamento, diagramas e gráficos. Além disso, as decisões de longo prazo em portfólio são, sobretudo, determinadas pela experiência e intuição da alta administração. Esses fatos demonstram certo grau de informalidade na gestão do portfólio de produtos na empresa.

Apesar de os meios financeiros serem reconhecidamente os mecanismos mais utilizados pelas empresas para a avaliação de projetos de novos produtos, o que foi confirmado no caso pesquisado, pode ser limitante a aplicação única desses critérios financeiros para a avaliação de portfólio de produtos em EBTs. Isso porque a avaliação financeira, muitas vezes, não consegue mensurar o impacto de determinada inovação tecnológica no mercado e, ainda, se concentra sobremaneira na estimativa de risco do projeto. Fazer somente esse tipo de avaliação pode, portanto, desestimular a execução de projetos de produtos mais inovadores ou ousados, tais como aqueles de inovação radical. 
Entende-se, dessa maneira, que para maior nível de informações e melhor capacidade de análise para a tomada de decisão sobre portfólio de produtos é importante que EBTs considerem também, conforme os seus objetivos e necessidades, a possibilidade de aplicação dos métodos financeiros em conjunto com um ou mais dos outros sugeridos ao longo deste artigo, fato confirmado pela literatura internacional.

A empresa estudada divide o processo decisório quanto ao portfólio de produtos em planejamento estratégico e revisões de portfólio. No caso, o PMO apoia a tomada de decisão nessas duas atividades. No planejamento estratégico, seu papel consiste em fornecer informações de mercado e de atributos técnicos de produtos e tecnologias, de modo a auxiliar o processo decisório da alta administração da empresa. Nas revisões de portfólio, o PMO participa diretamente das decisões de inovação incremental de produtos, uma vez que seus representantes participam das reuniões mensais em conjunto com a diretoria e o conselho de administração da empresa.

É importante frisar que esta pesquisa, de caráter qualitativo e exploratório, buscou obter compreensões iniciais sobre o papel do PMO na gestão do portfólio de produtos. Os resultados empíricos deste estudo devem, entretanto, ser vistos com a devida restrição metodológica, pois mesmo considerando que a empresa pesquisada renova seu portfólio de produtos com alta frequência e que ela possui PMO bem consolidado, devido à limitação do método de pesquisa empregado os resultados aqui apresentados não podem ser generalizados.

0 presente estudo demonstrou que devido ao alto teor tecnológico incorporado a seus produtos a empresa pesquisada encontra dificuldades para a obtenção de informações adequadas à previsão de demanda, o que dificulta o levantamento de indicadores financeiros para a tomada de decisão em portfólio de produtos. Estudos futuros poderiam replicar esta análise em outras empresas brasileiras de base tecnológica, de modo a observar se elas possuem dificuldades semelhantes, e também identificar como as EBTs realizam as análises financeiras para a tomada de decisão sobre quais produtos desenvolver, manter e retirar do mercado.

Com o objetivo de identificar outras práticas que o PMO pode adotar para apoiar a gestão do portfólio de produtos, futuras pesquisas também poderiam realizar estudos de casos em empresas que atuam em diferentes setores. Entende-se ainda que pesquisas quantitativas futuras poderiam ser realizadas com o intuito de verificar-se a influência do PMO no desempenho da gestão de portfólio de produtos.

\section{Referências}

Archer, N. P., \& Ghasemzadeh, F. (1999). An integrated framework for project portfolio selection. International Journal of Project Management, 17(4), 207-216. http:// dx.doi.org/10.1016/S0263-7863(98)00032-5

Artto, K., Kulvik, L., Poskela, J., \& Turkulainen, V. (2011). The integrative role of the project management office in the front end of innovation. International Journal of Project Management, 29(4), 408-421. http://dx.doi. org/10.1016/j.jproman.2011.01.008

Castro, H. G., \& Carvalho, M. M. (2010). Gerenciamento de portfólio: um estudo exploratório. Gestão \& Produção, 17(2), 283-296. http://dx.doi.org/10.1590/ S0104-530X2010000200006

Clark, K. B., \& Wheelwright, S. C. (1993). Managing new product and process development: text and cases. New York: The Free Press.

Cooper, R. G., Edgett, S. J., \& Kleinschmidt, E. J. (2000). New problems, new solutions: making portfolio management more effective. Research Technology Management, 43(2), 18-33.

Cooper, R. G., Edgett, S. J., \& Kleinschmidt, E, J. (1999). New product portfolio management: practices and performance. Journal of Product Innovation Management, 16(4), 331-351. http://dx.doi.org/10.1016/ S0737-6782(99)00005-3

Cosner, R. R., Hynds, E. J., Fusfeld, A. R., Loweth, C. V., Scouten, C., \& Albright, R. (2007). Integrating roadmapping into technical planning. Research Technology Management, 50(6), 31-48.

Crawford, L. (2002). The strategic project office. New York: Marcel Dekker.

Florén, H., \& Frishammar, J. (2012). From preliminary ideas to corroborated product definitions: managing the front end of new product development. California Management Review, 54(4), 20-43. http://dx.doi. org/10.1525/cmr.2012.54.4.20

Gibbert, M., \& Ruigrok, W. (2010). The "what" and "how" of case study rigor: three strategies based on published work. Organizational Research Methods, 14(4), 710-737. http://dx.doi.org/10.1177/1094428109351319

Hauser, J., Tellis, G. J., \& Griffin, A. (2006). Research on innovation and new products: a review agenda for marketing science. Marketing Science, 25(6), 687-717. http://dx.doi.org/10.1287/mksc.1050.0144

Heising, W. (2012). The integration of ideation and project portfolio management: a key factor for sustainable success. International Journal of Project Management, 30(5), 582-595. http://dx.doi. org/10.1016/j.jproman.2012.01.014

Jonas, D. (2010). Empowering projects managers: how management involvement impacts project portfolio management performance. International Journal of Project Management, 28(8), 818-831. http://dx.doi. org/10.1016/j.jproman.2010.07.002

Jugend, D., \& Silva, S. L. (2010). Práticas de gestão que influenciam o sucesso de novos produtos em empresas de base tecnológica. Revista Produção, 20(3), 335-346.

Kahn, K. B., Barczak, G., \& Moss, R. (2006). Perspective: establishing an NPD best practices framework. The Journal of Product Innovation Management, 23(2), 106116.http://dx.doi.org/10.1111/j.1540-5885.2006.00186.x 
Kavadias, S., \& Chao, R. 0. (2007). Resource allocation and new product portfolio management. In: C. H. Loch \& S. Kavadias (Eds.), Handbook of research in new product development management (pp. 135-163). Oxford: Butterworth-Heinemann.

Kester, L., Griffin, A., Hultink, E. J., \& Lauche, K. (2011). Exploring portfolio decision-making process. Journal of Product Innovation Management, 28(5), 641-661.

Killen, C. P. (2008). Project portfolio management for product innovation in service and manufacturing industries (Doctor thesis). Macquarie University, Sydney.

Killen, C. P., Hunt, R. A., \& Kleinschmidt, E. J. (2008). Project portfolio management for product innovation. International Journal of Quality \& Reliability Management, 25(1), 24-38. http://dx.doi. org/10.1108/02656710810843559

Mathews, S. (2011). Innovation portfolio architecture. Part 2: attribute selection and valuation. Research Technology Management, 54(5), 37-47. http://dx.doi. org/10.5437/08956308X5405005

McNally, R. C., Durmuşoğlu, S. S., \& Calantone, R. J. (2013). New product portfolio management decisions: antecedents and consequences. Journal of Product Innovation Management, 30(2), 245-261. http://dx.doi. $\operatorname{org} / 10.1111 / j .1540-5885.2012 .00997 . x$

McNally, R. C., Durmuşoğlu, S. S., Calantone, R. J., \& Harmancioglu, N. (2009). Exploring new product portfolio management decisions: the role of managers' dispositional traits. Industrial Marketing Management, 38(1), 127-143. http://dx.doi. $\operatorname{org} / 10.1016 /$ j.indmarman.2007.09.006

Miguel, P. A. C. (2007) Estudo de caso na Engenharia de produção: estruturação e recomendações para sua condução. Revista Produção, 17(1), 216-229. http:// dx.doi.org/10.1590/S0103-65132007000100015

Miguel, P. A. C. (2008). Implementação da gestão de portfólio de novos produtos: um estudo de caso. Revista Produção, 18(2), 388-404.

Mikkola, J. M. (2001). Portfolio management of R\&D projects: implications for innovation management. Technovation, 21(7), 423-435. http://dx.doi. org/10.1016/S0166-4972(00)00062-6
Oh, J., Yang, J., \& Lee, S. (2012). Managing uncertainty to improve decision-making in NPD portfolio management with a fuzzy expert system. Expert System with Application, 39(10), 9868-9885. http://dx.doi. org/10.1016/j.eswa.2012.02.164

Padovani, M., Carvalho, M. M., \& Muscat, A. R. N. (2012). Ajuste e balanceamento do portfólio de projetos: o caso de uma empresa do setor químico. Produção, 22(4), 651-673. http://dx.doi.org/10.1590/S0103-65132012005000064

Pedroso, C., Paula, 1. C., \& Souza, J. S. (2012). Análise comparativa de ferramentas de gestão de portfólio: um estudo de caso na indústria alimentícia. Produção, 22(4), 637-650. http://dx.doi.org/10.1590/ S0103-65132012005000078

Project Management Institute (2008). Project Management Body of Knowledge (3rd ed.). Pennsylvania: Project Management Institute.

Rodrigues, l., Rabechini Junior, R., \& Csillag, J. M. (2006). Os escritórios de projeto como indutores de maturidade em gestão de projetos. Revista da Administração, 41(3), 273287.

Scott, G. M. (2000). Critical technology management issues of new product development in high-tech companies. Journal of Product Innovation Management, 17(1), 5777. http://dx.doi.org/10.1016/S0737-6782(99)00012-0

Toledo, J. C., Silva, S. L., Mendes, G. H. S., \& Jugend, D. (2008). Fatores críticos de sucesso no gerenciamento de projetos de desenvolvimento de produto em empresas de base tecnológica de pequeno e médio porte. Gestão \& Produção, 15(1), 117-134. http://dx.doi.org/10.1590/ S0104-530X2008000100011

Unger, B. N., Gemünden, H. G., \& Aubry, M. (2012). The three roles of a project portfolio management office: their impact on portfolio management execution and success. International Journal of Project Management, 30(5), 608620. http://dx.doi.org/10.1016/j.ijproman.2012.01.015

Weissenberger-Eibl, M. A., \& Teufel, B. (2011). Organizational politics in new product development project selection: a review of the current literature. European Journal of Innovation Management, 14(1), 51-73. http://dx.doi. $\operatorname{org} / 10.1108 / 14601061111104698$

Yin, R. K. (2005). Estudo de caso: planejamentos e métodos (3. ed.). Porto Alegre: Bookman.

\title{
Contributions of the project management office to product portfolio management
}

\begin{abstract}
Although many studies have investigated the project management office, and substantial research has also examined product portfolio management, few studies have analyzed these elements together. This paper aims to identify how the project management office can contribute to product portfolio management. The research consists of a case study at a high-tech company where the product portfolio is continuously renewed and that features a wellestablished project management office. Among the main results, it was observed that the project management office's participation is greater during portfolio review decisions than during decisions related to the strategic planning of products. Furthermore, the project management office supports top management and the project teams in applying financial methods and in the mapping and evaluation phases during product portfolio management activities.
\end{abstract}

\section{Keywords}

Product portfolio management. Project management office. High-tech company. 


\section{Anexo 1. Síntese do roteiro de pesquisa.}

PARTE A. Caracterização da empresa

PARTE B. Gestão do portfólio de produtos e participação do Escritório de Projetos

- Como ocorre a gestão do portfólio de produtos na empresa? Quais as suas principais etapas? Explique como ocorre a participação do Escritório de Projetos em cada uma dessas etapas.

- Quão importante é a gestão do portfólio de produtos para a empresa? Há suporte da alta administração? Há suporte do Escritório de Projetos? Como isso ocorre?

- Como ocorre a tomada de decisões sobre quais produtos desenvolver na empresa? Existe estratégia já definida para isso? Como essa estratégia é formada (workshop, decisão individual, equipe multifuncional etc.)? Quão formal é isso? Como ocorre a participação do Escritório de Projetos nessas decisões?

- Quais áreas/departamentos participam da gestão do portfólio de produtos na empresa? Quais são considerados mais importantes nessas decisões?

- Existem regras claras para a gestão do portfólio de produtos na empresa? Os projetos são comparados e priorizados? Quais procedimentos são usados para isso?

- Como são determinados quais projetos de produtos devem ser desenvolvidos, interrompidos e priorizados? Existem critérios previamente definidos para isso? 0 Escritório de Projetos participa dessas definições?

- Explique como o Escritório de Projetos apoia a gestão do portfólio de produtos da empresa.

Aplicação dos métodos formais na gestão de portfólio de produtos e participação do Escritório de Projetos. Assinale e discorra sobre os métodos efetivamente aplicados pela empresa.

\begin{tabular}{|l|l|l|l|}
\hline \multicolumn{1}{|c|}{ Método } & Como é operacionalizado? & $\begin{array}{c}\text { Quais são os benefícios e } \\
\text { dificuldades na utilização } \\
\text { desse método? }\end{array}$ & $\begin{array}{c}\text { Como ocorre a } \\
\text { contribuição do Escritório } \\
\text { de Projetos para a } \\
\text { aplicação do método? }\end{array}$ \\
\hline $\begin{array}{l}\text { ( ) Financeiro } \\
\text { Quais métodos financeiros são utilizados (payback, } \\
\text { valor presente líquido e taxa interna de retorno, por } \\
\text { exemplo)? }\end{array}$ & & & \\
\hline () Avaliação de fases & & & \\
\hline ( ) Mapas de produtos & & & \\
\hline ( ) Modelos de pontuação & & & \\
\hline ( ) Diagramas (bolhas, matriz BCG, e GE, por exemplo) & & & \\
\hline ( ) Checklist & & & \\
\hline $\begin{array}{l}\text { ( ) Outros } \\
\text { lndicar }\end{array}$ & & & \\
\hline
\end{tabular}

